\title{
Provocative Counseling Technique on Students-Aspirants of Professional Institutes at Indian BOP-Segment
}

\author{
${ }^{1}$ Prof. Bhudhar Ranajan Chatterjee, ${ }^{2}$ Sukanya Chatterjee \\ ${ }^{I}$ Associate-Prof / Head, Dept. of Management, ${ }_{2}$ S R Group of Institutes, Ambabai, Jhansi-284002, UP,India.
}

\begin{abstract}
Students aspiring for Professional Education, such as Engineering, Management, belonging to low and mid-income group, are a confused lot. The parents with low level of education have hardly any knowledge of accreditation mechanism for a particular Institute in and around his locality. Since standardization of Educational, quality in India is at a nascent stage, Students and Parents at the low-end Education and Income level, suffer the worst confusion in admission into an Institute.

The present Research, being a pioneering effort on Student-Counseling at the BOP segment of the Society, would try to empirically conclude the relationship between Selection of a particular Institute and its Placement Standard.

Whether persuasive counseling can be classified as Provocative, may be an issue of debate but the present Research would like to probe into the efficacy of the Provocative Selling technique in Educational/Institutional marketing at the BOP Segment in India.

As many Researchers ( Jaywalk, Karnani) vehemently argued, whether OPPORTUNITY really exits at the Bottom or the Mid of the Pyramid, is of another issue and research, the present Research would endeavor to focus on the Mid level of our society.
\end{abstract}

Keywords: BOP Segment, Student-Counseling ,Provocative Selling.

\section{Overview:}

Opening up the Education sector for Private players, has thrown varieties of challenges for all stake holders, particularly for the Students at Low and Mid level of our Society.

Students at Lower and even Mid segment, normally follow a pre-designated, well - laid path of high paid jobs and companies with high Brand, placement being the only objective of professional education.

Under such a confusing situation, this Research would strive hard to come to some reasonable conclusion as how Provocative counseling can have a definitive effect on choice/selection of a particular Institute.

There have been a lot of research in innovative selling- techniques for different products/services in different challenging situations, but in an unprecedented recession in US/EUROPE, when the Buyer - resistance grew manifold, marketers had to resort to innovative selling techniques. A few Marketers wanted to focus on a large market segment, existing at the Bottom of Pyramid in Emerging Markets. A billon people as customers in India at BOP segment, should be a large enough allurement for any Marketer of a multinational corporation.

They finally found out some innovative skills and techniques to succeed in such trying situations and termed that technique as Provocative Selling Technique. Here the customers are supposed to see their competitive challenges in a new light, that made Firms to address Customer - Problem and need, hitherto unheard of, unattended, and even unnoticed. Consumers at the BOP segment usually restricted their consumption a great deal but still had some problem areas not assessed, needed to be addressed.

C.K. Prahalad conceptualized and vehemently propagated BOP and stated that there lies a huge market of billions of people in Emerging Markets as potential customer, who earns less than \$ 2 a day. Prof. Prahalad also advocated As "we must stop thinking that these billion people are a drag on our economy, rather they are resilient and value-conscious consumers and an unforeseen door of opportunity may be opened."

Creating Leaders at the BOP level through various successful experiments by ITC / AMUL/ JAIPUR RAGS / SHAKTI AMMAS - HLL/ICICI BANK -SHG and so on, are there in India. This Co-creation of Leadership culture has made a huge difference in Socio-economic fabric of rural India.

Contemporary Research on the Topic (Literature Review):

* The concept of Provocative selling was originally propagated by three eminent Marketers, Philip Lay, Todd Howling, Geoffrey Moore and published in the 2008, March Edition of HBR with the objective of developing an Unique selling model to succeed in a recessionary situation.

The model is different from the usual concept of Transactional or Relationship approach. 
- $\quad$ Prof. David Brook through a publication on $21^{\text {st }}$ August,09, disagreed with the model published by David Moore and argued that :

a) it created a Hype / Crisis situation and captured attention through gimmick.

b) it only could be considered as an Wake-up Call for the complacent companies as "every successful company must have been Provocative in its selling approach at some point of time."

- Niall Davitt in his research in March, 09 argued if "Provocative Selling is a new kind of Selling Eloquence? He argued that "academicians should be able to help the companies to help their customers, which requires a combination of Knowledge, Skill and Expertise."

- $\quad$ Keith Eades, CEO, Sales \& Performance International, disagreed through his paper and stated Provocative Selling is based on the same platform of Solution Selling ( he claimed as his own concept).

The technique of Provocative Selling can well be applied to a Bottom of the Pyramid segment in emerging markets like India, where a billion people can be converted into customers as shown by C.K.Prahald. $\mathrm{He}$, through his revolutionary book, "Fortune at the Bottom Pyramid" that " we must stop thinking that these billion people are a drag on our Economy, rather than they are resilient and value conscious consumers and an unforeseen door of opportunity may be opened." He also emphatically stated that these 4 billion people would form the next round of Platform of Global Trade.

\section{Objective :}

The Present Research is a pioneering attempt to understand the relationship and potential impact of Provocative Selling / Solution Selling approach in Student-Counseling for selecting a Professional Educational Institute.

Privatization in Indian Education Sector has enacted a sea change in the sector. The sector which was being subsidized and run by the Govt.-Monopoly became an Industry, overnight.

This present research would endeavor to throw light on Student's behavioral pattern for selecting a particular Institute on the basis of Placement-standard, since this has become the pivotal element in choosing a particular Institute.

There is hardly any doubt that the Indian economy would again recapture its earlier growth momentum from $4^{\text {th }}$ quarter of the current or $1^{\text {st }}$ quarter of next year, the Mid level of Indian market is again poised to grow at a phenomenal pace.

It would provide clues to develop such product and services for the BOP segment.

Inclusive growth in an Economy like India, could easily be achieved through BOP marketing. Empowering the BOP consumers would remain a challenge for BOP marketing.

The present study, against the said backdrop would be of special interest for our social perspective.

This Research would be able to lay down a Road - Map and a Model for similar Industries in India/Emerging markets to accept the help of the Provocative Selling Technique, when their sales - curve is on the decline under a recession like situation.

Provocative Selling Technique, in spite of the criticism and controversy, stand out to be very effective tool for success under such condition, in view of the Researcher, we further intend to focus our Research on the BOP segment of the Institute, since the sample would constitute of Institutes, where the total cost of 2 year program is not more than Rs.3 lacs. In actual terms, it can be considered as the Middle of the Pyramid.

\section{Alternative Perspective /Arguments:}

Prof. A.K. Jaiswal of IIM-A in 2005 stated that in 2002, CK.Prahalad and Stuart Hurt erroneously contended that big MNC's only targeted high - end ( upper-end of the Pyramid) customers ignoring the BOP segment. His major contention was:

a. We must avoid undesirable Inclusion and Exclusion in the BOP segment .Inclusion : Products who satisfy the basic needs : health, nutrition, education etc. which can enhance the well-being of the BOP consumers Exclusion : Products of mere consumption purpose which do not contribute to the well being of the BOP consumers Failure to provide goods/services which enhance their well-being.

b. $\quad$ Estimate of the World Bank that in 2001, nearly 1.1Billion people earns less than \$1 daily, and can not be a part of any profitable market segment of a large company.

Therefore he argued that Fortune exists only at the Lower Middle and Middle of the Pyramid and not at the Bottom.

* Prof. Karnani(2007) argues that if the objective is to reduce Poverty than the BOP people should not be regarded as Consumers but Producers, as he said that we need to facilitate production by poor and support them to selective consumption for their well being.

He argued that consumption of welfare goods also helps raise their income. Ex :Health insurance reduces the risk and cost of medical treatment reducing the loss of productivity. 
Dr. Siamanis in his research in 2009 stated that "Companies should start by getting communities involved in creating, implementing and shaping the business itself. The sense of ownership brings thus, will help ensure that interest these company's products would be wide-spread and sustained."

- Prof. Cris. went a step further and stated that " the sense of ownership across the spectrum of Education, Business and Environment is the key to consistent upward growth of an Economy."

\section{Sample Size :}

Bundelkhand region in UP, being the locational parameter of the present study, has 6 AICTE approved Technical Institutes and that being the Population and to arrive at a reasonable degree of confidence, we would select 3 larger Institutes and 100 students randomly, from each Institute.

We would like to take help of PVASS - Pensylvania Value Added System ( Tribune Business News, Washington - Feb'2011. A statistical Method of measuring Influence of School Program o Academic growth of each or a group of students.)

\section{Perspective of the Research Study :}

Though the proposed study has Retrospective elements in nature, its findings have all the Prospective and Long - term potentiality for the recession hit Industries in India.

CK Prahlad through extensive research on 700 market segments on Social Change , 70 plus Site Visits/Interviews with stake-holders and 1500 customers, reveal that barriers are such as 1) Uncertain CashFlows 2) Changing Demand (confusing Need with Demand) 3) Distribution Challenge BOP clearly is not for every company even if it is highly motivated. Researchers came up with the following questions :

1. Can we manage Large no of Low margin, Low value transactions

2. Can we work with Informal Markets.

3. Do leaders have a long - term mind set.

1. Can we keep out legacy and Over head Costs.

2. Will Organizational Culture stifle a BOP innovation

But they have concluded that the solution lies in Creating New Business Model.

\section{Methodology :}

Study would be undertaken on the basis of a sample Survey with the help of a Questionnaire. The Questionnaire has been designed in both English and Hindi to elicit the correct response from the respondents, selected randomly.

The Researcher decided to undertake a Market - Research Analysis under the concept of MAXIMUM DIFFERENTIAL SCALLING TECHNIQUE (MAX-DIFF) .

This popular and very handy technique was first practiced by Jordan Louviere in 1987 with very simple 6 steps such as :

1. Select Attributes

2. Show it to potential customer

3. Plan the sample survey

4. Respondents to choose BEST - WORST

5. Find out the Score

6. Analyze Data to arrive at conclusion.

We would take the help of basic concept of Conjoint Analysis to obtain estimates of the Main Effects of the Variables. The terminology of describing such conjoint importance in determining the Weights, is in terms of - SCORE/UTILITY. We also intend to analyze the Data on the basis of Percentage and Rank Findings.

Table-1

\begin{tabular}{|c|l|c|c|}
\hline S. No. & Attribute & Most & Least \\
\hline & & $\square$ & - \\
\hline 1 & Tech/MBA Student target only Jobs with highest - Salary & $\square$ & - \\
\hline 2 & Brand-Value of a Company is the foremost Issue & $\square$ & - \\
\hline 3 & Job Security in the Prime Issue in final Choice. & - & $\square$ \\
\hline 4 & Salary is not an issue. & & \\
\hline
\end{tabular}


Table-2

\begin{tabular}{|c|l|c|c|}
\hline S. No. & Attribute & Most & Least \\
\hline 1 & Brand-Value of a Company is most important factor. & - & $\square$ \\
\hline 2 & Job Security is the most & $\square$ & - \\
\hline 3 & Salary not a factor at all & - & $\square$ \\
\hline 4 & Job Security is not a factor & - & $\square$ \\
\hline
\end{tabular}

Table-3

\begin{tabular}{|c|l|c|c|}
\hline S. No. & Attribute & Most & Least \\
\hline 1 & Brand-Value of a Company is most important factor. & - & $\square$ \\
\hline 2 & Job Security is the most & $\square$ & - \\
\hline 3 & Salary not a factor at all & - & $\square$ \\
\hline 4 & Job Security is not a factor & - & $\square$ \\
\hline
\end{tabular}

Table-4

\begin{tabular}{|c|l|c|c|}
\hline S. No. & Attribute & Most & Least \\
\hline 1 & Security is not a factor & - & $\square$ \\
\hline 2 & Brand-Value of a Company is most important. & $\square$ & - \\
\hline 3 & Job Security is the final issue. & $\square$ & - \\
\hline 4 & Promotion-Potentiality is the Main Issue. & $\square$ & - \\
\hline
\end{tabular}

TABULATED RESULT SCORE

Table-5

\begin{tabular}{|c|l|c|}
\hline S. No. & Attribute & Most \\
\hline 1 & Tech/MBA Student target only Jobs with highest - Salary & 10 \\
\hline 2 & Salary is a major, but not the most important factor & $20^{*}$ \\
\hline 3 & Salary is a less important issue & 5 \\
\hline 4 & Only Dignified Job is the main issue & 5 \\
\hline 5 & Brand of the Company is Most sought after issue & 15 \\
\hline 6 & Office Job is the most is most sought after & 5 \\
\hline 7 & Job-Security is the Prime issue & $25^{*}$ \\
\hline 8 & Security is least important issue & 5 \\
\hline 9 & Look of the office is most important & 5 \\
\hline 10 & Promotion opportunity is the main issue & 5 \\
\hline
\end{tabular}

\section{CONCLUSION / FINDINGS :}

The final scores/ findings unambiguously predict that Student - Preference/Choice actually associates with the most Problem area - Placement and there can be the distinct solution to the problem, the Institutes have been searching all the time.

The $7^{\text {th }}$ and the $2^{\text {nd }}$ attribute securing score of 25 and 20 respectively, with highest scores, clearly proved that Job-Security and Salary are closely related to Final Choice for admission in a particular Institute.

The results of the Market Research was spectacular, in the sense, that the Institutes at the Mid/Bottom segment, though having a sense, now can be assured of Main Choices of a Student .

Test of Significance / Second Approach :

RANKING AND TEST OF SIGNIFICANCE

We have graded the Attributes as per their Rankings and considered 4 attributes with reasonably higher score to arrive at the conclusion, which may or may not conform to the findings of the $1^{\text {st }}$ approach $\quad$ (MAXDIFF). 
1- Job Security is the most important.

2- Salary is a major but not the Most important 20

3- Brand Value of a Company is the Most Important 15

4- Students target the Highest Salary

To test the significant difference in the ranking of different perception of students and parents on the Utility / Value of Placement in Professional Institutes, Chi-Square analysis and Friedman Two-way ANOVA study were undertaken to arrive and calculate Mean - Ranks.

The Null and Alternative Hypothesis have been framed as under:

Ho: There is No Difference in Student / Parent perception on Placement.

H1: There is Significant Difference in Student / Parent perception on Placement.

Table-6

\begin{tabular}{|c|l|c|c|}
\hline S. No. & Attribute & $\begin{array}{c}\text { Mean Ranks } \\
(\mathrm{N}=1001)\end{array}$ & Chi Square 5\% \\
\hline 1 & Students target the Highest Salary & 2.60 & \\
\hline 2 & Brand Value of a Company is the Most Important & 2.58 & $57.70(0,000)$ \\
\hline 3 & Salary is a major but not the Most important & 2.42 & \\
\hline 4 & Job Security is the most important & 2.20 & \\
\hline
\end{tabular}

Table 6, Once again implies that "Job Security" is the most significant Attribute (Mean Rank $=2.20)$ whereas "Students target only highest Salary", has been relegated to the Most insignificant attribute, as per the prevailing perception of the existing students and their parents.

Analysis of the results on Test of Significance also leads to the Chi-Square value of 57.70, which is quite significant $(\mathrm{p}=0.000)$ at 5\% Level, thereby rejecting the Ho Hypothesis and accepting $\mathrm{H} 1$ at 5\% level, clearly implying variation in perception of the respondents.

In spite of voluminous arguments and empirical findings that Middle of Pyramid should be the most sought after segment in the developing economies, like India, Bottom of Pyramid remains the largest and best space of all opportunity, in the coming days.

\section{Implication Of The Research:}

The present research may be a benign study which has endeavored to apply Provocative Selling Technique to offer solutions in the BOP segment of a relatively small/medium scale Industry and particularly where the Pain - Points of the Customers/Students are unique.

Similar studies, if undertaken in the BOP segment of products/services of large scale Industries, may open new vistas for MNCs, who are looking for such opportunities is emerging market economies, like India.

[1] Fortune at the Bottom of Pyramid

[2] Gurus on People Management

[3] HBR

[4] Marketing Theory

[5] Marketing Research

[6] Consumer Behavior

[7] Vikalpa (IIM - A)

[8] Decision (IIM - K)

\section{References / Sources}

\author{
Prof. C.K. Prahalad \\ Prof. Sultan Kermally \\ March / April, 2009 \\ Jan / March , 2009 \\ The Journal of Marketing, Jan, 84 \\ Leon Schiffman \\ 2003/March \\ 2004/Oct
}

